\title{
Effects of Soil-Transmitted Helminths and Intestinal Protozoan Infections on Haemoglobin Levels among School-Aged Children in Belo and Bui, North West Cameroon: A Cross- Sectional Study
}

\author{
Frederick Nchang Cho $\mathbb{D}^{1,2,3,4}$ Humphrey Ngala Ngala, ${ }^{5}$ Ranibell Tung Bongazi, ${ }^{5}$ \\ Rogers Sanga Kinsam, ${ }^{5}$ Beltha Tahnteng Tata, ${ }^{5}$ Desmond Aji, ${ }^{6,7}$ Paulette Ngum Fru $\mathbb{D}^{8,9}$ \\ and Patrick Kofon Jokwi ${ }^{5,7}$
}

\author{
${ }^{1}$ Department of Biochemistry and Molecular Biology, Faculty of Science, University of Buea, P.O. Box 63, Buea, Cameroon \\ ${ }^{2}$ Infectious Disease Laboratory, Faculty of Health Sciences, University of Buea, P.O. Box 63, Buea, Cameroon \\ ${ }^{3}$ Central African Network for Tuberculosis, HIVIAIDS and Malaria (CANTAM), University of Buea, Buea, Cameroon \\ ${ }^{4}$ Global Health Systems Solutions, Cameroon \\ ${ }^{5}$ Catholic School of Health Sciences, Saint Elizabeth Hospital Complex, P.O. Box 8 Shisong-Nso, Cameroon \\ ${ }^{6}$ Department of Microbiology and Parasitology, Faculty of Science, University of Buea, P.O. Box 63, Buea, Cameroon \\ ${ }^{7}$ Cameroon Baptist Convention Health Board (CBCHB), Kumbo, Cameroon \\ ${ }^{8}$ Department of Public Health and Hygiene, Faculty of Health Sciences, University of Buea, P.O. Box 63, Buea, Cameroon \\ ${ }^{9}$ District Health Service Tiko, South West Regional Delegation of Health, Ministry of Health, Cameroon
}

Correspondence should be addressed to Frederick Nchang Cho; nchang.cho@gmail.com

Received 27 August 2020; Revised 15 January 2021; Accepted 20 January 2021; Published 1 February 2021

Academic Editor: John Kagira

Copyright ( 2021 Frederick Nchang Cho et al. This is an open access article distributed under the Creative Commons Attribution License, which permits unrestricted use, distribution, and reproduction in any medium, provided the original work is properly cited.

\footnotetext{
Introduction. Soil-transmitted helminths (STH) remain a public health problem worldwide especially in low-income countries. Soil-transmitted helminths are known to affect both growth and haemoglobin levels. In this study, we determine the prevalence of intestinal parasites and explored its association with anaemia in school-aged children (SAC). Methodology. A cross-sectional study was carried out amongst pupils selected from 18 primary schools in four communities of the North West Region. Stool samples were examined using direct wet mount and formol-ether concentration techniques, while finger prick was performed for the measurement of haemoglobin with a haemoglobinometer. Results. The results showed significant variation of STHs, intestinal protozoan prevalence, and anaemia between age, sex, and communities. The prevalence of Ascaris lumbricoides, Trichuris trichiura, and hookworms was $15.1 \%, 0.8 \%$, and $2 \%$, respectively, with an overall STH prevalence of $18.3 \%$ across the four communities. Soil-transmitted helminths were more prevalent in Mbessa (30.2\%) in comparison to Nkor (26.7\%), Djottin (17.5\%), and Kumbo (9.6\%) communities. The prevalence of Entamoeba histolyticaldispar was $25.4 \%$ and Giardia duodenalis (6.9\%), with an overall intestinal protozoa prevalence of $31 \%$ across the four communities. The prevalence of anaemia in the study population was $23.1 \%$. Conclusion. Soil-transmitted helminths, intestinal protozoan infections, and anaemia are prevalent in the study area. Anaemia was observed to be associated with STH, intestinal protozoa, and the communities under study. This study recommends continuous deworming and health education on personal sanitation and environmental sanitation.
} 


\section{Introduction}

Soil-transmitted helminths (STHs) infect more than two billion people in more than 100 countries of the world, while intestinal protozoan infections remain a public health problem in low- and middle-income settings of tropical and subtropical countries; however, epidemiological evidence is scarce in most areas [1-5]. Intestinal parasitic infections, STH, and intestinal protozoan infections are amongst the most prevalent diseases in sub-Sahara Africa [6-9], with about 267 million preschool age children and 568 million school-aged children (SAC) at risk of chronic infections in Africa with the consequence being anaemia [10]. Anaemia in general is also a public health concern and is very prevalent amongst SAC in developing countries [11-15]. Iron deficiency anaemia and malnutrition which are also associated with infectious diseases also constitute a public health concern in low- and middle-income countries [16-18]. The number of persons infected per million by STHs in mostly Africa and Asia are Ascariasis (1,22114,472), Trichuriasis (759-1050), and Hookworm infection (740-1300), while the number of deaths/years in thousands caused by these agents are 3-60,3-10, and 3-65, respectively. Soil-transmitted helminths constitute a problem worldwide [19-21] and in Africa [22-24].

In Cameroon, the prevalence of Ascaris lumbricoides, hookworm, and Trichuris trichiura was $28.1 \%, 9.8 \%$, and $6.3 \%$, respectively [4]. Soil-transmitted helminth infections are endemic in Cameroon [25], are found everywhere including the North West Region, and are common amongst SAC $[4,26]$. Entamoeba histolytica/dispar is a common parasite in the large intestine of humans, other primates, and some other animals. In Muyuka-Cameroon, the rate of E. histolyticaldispar in SAC was reported to be $18.4 \%$ [6]. Giardia duodenalis, a flagellate, is the only common protozoa found in the duodenum and jejunum of humans [27] and has been reported amongst prison inmates in Douala [28] as well as amongst children in the Nyong et Mfoumou Division [29] and Bolifamba in Buea [26]. In a study to map shistosomiasis and helminthiasis in four regions of Cameroon, the overall rates of STH, ascaris, T. trichiura, and hookworm were $32.5 \%, 19.5 \%, 18.9 \%$, and $7.6 \%$, respectively, and ascaris, hookworm, and T. trichiura were $28.1 \%, 9.8 \%$, and $6.3 \%$ in the North West Region [4].

The magnitude of STH and intestinal protozoan infections are scarcely studied among pupils in Belo and Bui Divisions of Cameroon. However, a study conducted in selected schools in the centre, east, and west regions indicated that despite the annual administration of preventive chemotherapy, STH and intestinal protozoan infections remain a serious public health problem amongst pupils. The current study seeks to assess the prevalence of STH, intestinal protozoan infections, and their associations with haemoglobin concentration amongst primary school pupils in four communities of the northwest region of Cameroon.

\section{Materials and Methods}

2.1. Study Design. This cross-sectional study was conducted between December 2015 and April 2016 in two divisions of the northwest region of Cameroon. The study participants were asymptomatic primary school pupils. The sample size was calculated based on the Cochrane formula $n=Z^{2} p q / d^{2}$ $[30,31]$, where $n$ represented the sample size; $Z$ was 1.96 which is the standard normal deviation (for a 95\% confidence interval), $p$ was $32.5 \%$ [4], the proportion of STH prevalence; $q$ was $1-p$, the proportion of STH negative; and $d$ was 0.05 , the acceptable margin of error. The minimum sample size per cluster/community was estimated to be 337 . Considering a possible loss of samples due to deterioration and nonconsenting to participants, the sample size was adjusted by $10 \%$ to a minimum of 371 per cluster. In this study, community and locality were used interchangeably to mean a group of people living together under similar environmental and climatic conditions.

2.2. Study Area and Population. This study was carried out in four communities in Belo and Bui Divisions of the North West Region (Figure 1). These communities are situated in the grassland area of Cameroon.

Kumbo is the administrative headquarter of Bui Division, and it is made up of two health districts, Kumbo East and West Health Districts. Kumbo has a District Hospital, two referral hospitals, and several Integrated Health Centres. Mbessa in Belo is situated on latitude $5.70773^{\circ}$ north of the equator and longitude $10.3026^{\circ}$ east of the Greenwich meridian. Mbessa has the Akeh Baptist Health Centre. These "grass field" localities have two main seasons: the rainy season, which lasts from mid-March to October, and the dry season, which lasts from November to early March.

The planning of these localities is natural, with scattered settlements around farmlands, linear settlements along main roads, and nucleated settlements. However, farms are clustered around settlements. The roads are not tarred, thus dusty in the dry season and muddy in the rainy season. Hospital records show that intestinal parasitic infections occur all year round, with peaks at the beginning of the rainy season.

Eligible participants were pupils aged 4-15 years who resided in the study area and were not on any antihelminthic or antiparasitic drugs for at least four weeks prior to specimen collection.

2.3. Ethical Consideration. The study was approved by the Divisional Delegates of Basic Education for Belo and Bui, the Educational Authorities for the Cameroon Baptist Convention and Catholic schools, Cameroon, and was conducted in accordance with the Helsinki declaration [32]. Administrative clearances were obtained from the various head teachers. Also, parents or guardians signed consent forms on behalf of their children and assent was obtained from the pupils.

2.4. Sampling Techniques and Data Collection. We used multistage cluster sampling where a list of all the administrative divisions, communities therein, and schools was drawn. Two of the seven administrative divisions of the region were selected for the study. At least two schools were selected from each community, resulting in a total of 18 primary schools. 


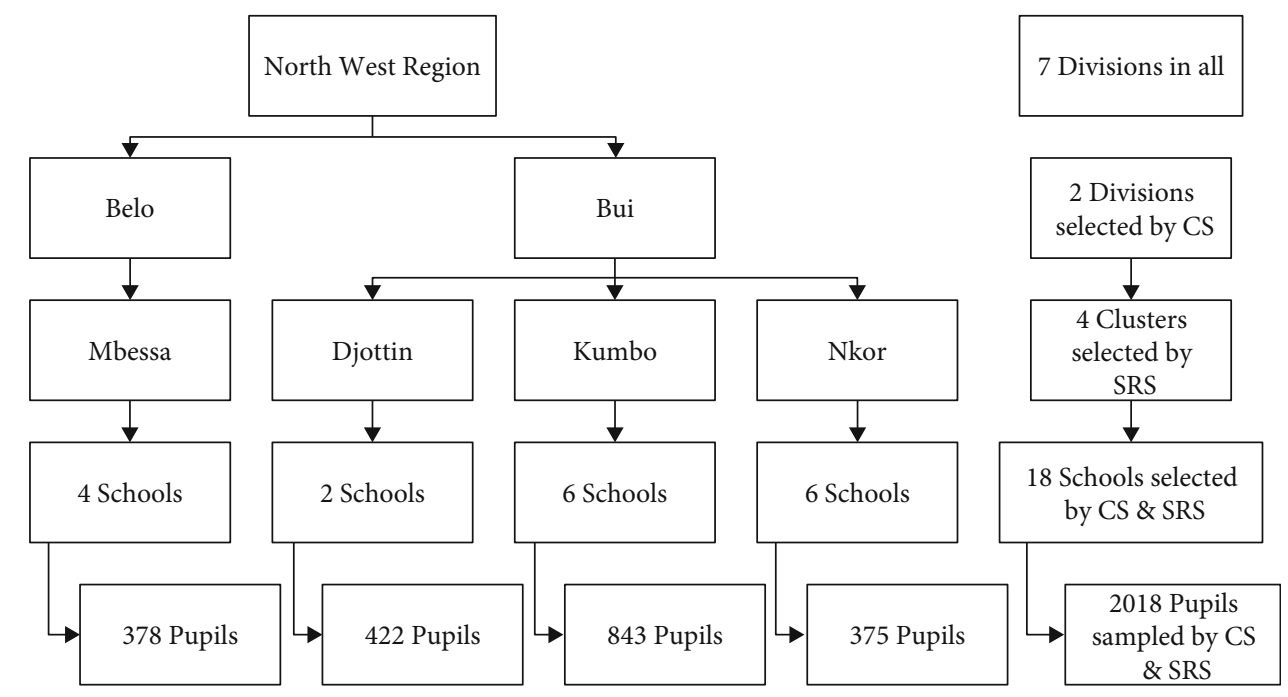

FIGURE 1: Multistage sampling of pupils (CS: convenience sampling; SRS: simple random sampling).

The sampling procedure of the required number of pupils was done in two stages.

2.4.1. Stage One. We drew up a list of communities in the selected divisions and four communities: Djottin, Kumbo, Mbessa, and Nkor were selected using simple random sampling (SRS) (Figure 1). This was followed by compiling a list of the primary schools obtained from the educational authorities for each selected community, and the required number of schools was selected by either SRS or convenience sampling.

2.4.2. Stage Two. Within each selected school, pupils were selected as follows: for small class sizes (less than 30 pupils), the entire class was selected. For classes with more than 60 pupils (the average class size in Cameroon is 50 pupils [33]), the systematic random sampling approach was used. From the class list of each class, every third or fourth pupil was sampled depending on the number of pupils in the class (Figure 1). Basic demographic data like age and sex were obtained from class registers.

2.5. Specimen Collection and Examination. Specimen collection was preceded by health education on the purpose of the study and instructions on how to collect stool. Once participants' parents gave consent and participants gave assent, stool specimens were collected into labelled stool containers [34] in the morning of the following day and stored in a cool box (regulated the temperature to $<20^{\circ} \mathrm{C}$ ) for transportation to the Parasitology Laboratory of the Catholic School of Health Sciences (a three-hour drive from the furthest community; Mbessa). Respondents were instructed to put about a teaspoonful amount of stool into leak-proof wide-neck stool containers. Stool collection was followed by a finger prick for the measurement of haemoglobin with a haemoglobinometer, and pupils with values less than $12 \mathrm{~g} / \mathrm{dL}$ were considered to be anaemic in this study $[35,36]$. Anaemia was categorised based on the WHO [36] criteria as follows; mild
$(10-11 \mathrm{~g} / \mathrm{dL})$, moderate $(8-9 \mathrm{~g} / \mathrm{dL})$, marked $(6-7 \mathrm{~g} / \mathrm{dL})$, severe $(4-5 \mathrm{~g} / \mathrm{dL})$, and critical $(<4 \mathrm{~g} / \mathrm{dL})$.

Stool was analysed with the normal saline wet mount and the formol-ether concentration techniques as described elsewhere [34]. Parasites were identified by light microscopy (Olympus Optical Co., Ltd, Japan) maximum 4-6 hours after collection [34].

2.6. Statistical Analysis. Data collected were entered into Microsoft excel, 2016 (Microsoft Corporation Inc. USA) and transported to the Statistical Package for Social Sciences version 25.0 (IBM-SPSS, Inc., Chicago, IL, USA) for analysis. The Chi-square $\left(\chi^{2}\right)$ and odds ratios (O.R) were used to determine the association between parasite, sex, and anaemia. Statistical significance was set at $p<0.05$.

\section{Results}

3.1. Characteristics of the Study Participants. Of the 2018 participants, $422(20.9 \%)$ were from Djottin, $843(41.8 \%)$ from Kumbo, 378 (18.7\%) from Mbessa, and 375 (18.6\%) from Nkor. The proportion of males $(49.0 \%)$ and females $(51.0 \%)$ in the study population were similar. Most of the participants were adolescents (94.5\%) while very few were toddlers (5.5\%) (Table 1).

3.2. Soil-Transmitted Helminths and Intestinal Protozoan Prevalence. Overall a total of 369 (18.3\%) and 626 (31.0\%) participants were infected with at least one species of STH and intestinal protozoa compared to the $1649(81.7 \%)$ and 1392 (68.9\%) uninfected participants, respectively (Table 1). Sex and age distribution were comparable between the two groups. The most prevalent STH species in the study participants were A. lumbricoides (15.1\%) and N. americanus (2.0\%). The proportion of participants infected with Strongyloides stercoralis $(0.8 \%)$ and with $T$. trichiura $(0.8 \%)$ was clearly lower. Three hundred and fifty-nine (17.8\%) participants were infected with one STH species only and 10 $(0.5 \%)$ with two STH species. The intestinal protozoan found 
TABLE 1: Characteristics of the study population in association with STHs and intestinal protozoan infections.

\begin{tabular}{|c|c|c|c|c|}
\hline Variable & Total & STH negative & STH positive & $p$ value \\
\hline Soil-transmitted helminthiasis & $(n=2018)$ & $(n=1649)$ & $(n=369)$ & \\
\hline Adolescents (5-15 years) & $1908(94.5)$ & $1580(95.8)$ & $328(88.9)$ & $<0.001$ \\
\hline Toddlers ( $3-4$ years) & $110(5.5)$ & $69(4.2)$ & $41(11.1)$ & \\
\hline Age (years) $(\bar{x} \pm S D)$ & $8.3 \pm 2.5$ & $8.4 \pm 2.5$ & $7.6 \pm 2.5$ & $<0.001$ \\
\hline Anaemic for at least one STH & $467(23.1)$ & $341(20.7)$ & $126(34.1)$ & $<0.001$ \\
\hline Haemoglobin $(\mathrm{g} / \mathrm{dL})(\bar{x} \pm \mathrm{SD})$ & $12.9 \pm 2.1$ & $13.1 \pm 2.0$ & $12.4 \pm 2.2$ & $<0.001$ \\
\hline Female $N(\%)$ & $1029(51.0)$ & $793(48.1)$ & $236(64.0)$ & $<0.001$ \\
\hline Male $N(\%)$ & $989(49.0)$ & $856(51.9)$ & $133(36.0)$ & \\
\hline Ascaris lumbricoides N (\%) & $304(15.1)$ & & $304(82.4)$ & $<0.001$ \\
\hline Strongyloides stercoralis N (\%) & $17(0.8)$ & & $17(4.6)$ & $<0.001$ \\
\hline Hookworm N (\%) & $41(2.0)$ & & $41(11.1)$ & $<0.001$ \\
\hline Trichuris trichiura $N(\%)$ & $17(0.8)$ & & $17(4.6)$ & $<0.001$ \\
\hline Two STH species infection $N(\%)$ & $10(0.5)$ & & $10(2.7)$ & $<0.001$ \\
\hline \multirow[t]{2}{*}{ Single STH species infection $N(\%)$} & $359(17.8)$ & & $359(97.3)$ & \\
\hline & & $\begin{array}{l}\text { IP negative } \\
(n=1392)\end{array}$ & $\begin{array}{l}\text { IP positive } \\
(n=626)\end{array}$ & \\
\hline Adolescents (5-15 years) & & $1352(97.1)$ & $556(88.8)$ & $<0.001$ \\
\hline Toddlers (3-4 years) & & $40(2.9)$ & $70(11.2)$ & \\
\hline Age (years) $(\bar{x} \pm \mathrm{SD})$ & & $8.5 \pm 2.4$ & $7.7 \pm 2.6$ & $<0.001$ \\
\hline Anaemic for at least one IP & & $294(21.1)$ & $173(27.6)$ & 0.001 \\
\hline Haemoglobin $(\mathrm{g} / \mathrm{dL})(\bar{x} \pm \mathrm{SD})$ & & $13.1 \pm 2.0$ & $12.6 \pm 2.1$ & $<0.001$ \\
\hline Female $N(\%)$ & & $679(48.8)$ & $350(55.9)$ & 0.003 \\
\hline Male $N(\%)$ & & $713(51.2)$ & $276(44.1)$ & \\
\hline Entamoeba histolytica/dispar N (\%) & $512(25.4)$ & & $512(81.8)$ & $<0.001$ \\
\hline Giardia duodenalis N (\%) & $139(6.9)$ & & $139(22.2)$ & $<0.001$ \\
\hline Two IP species infection $N(\%)$ & $25(1.2)$ & & $25(4.0)$ & $<0.001$ \\
\hline Single IP species infection $N(\%)$ & $601(29.8)$ & & $601(96.0)$ & \\
\hline
\end{tabular}

SD: standard deviation; $\bar{x}$ : mean; STH: soil-transmitted helminths; IP: intestinal protozoan; boldface numbers indicate significant $p$ values.

in the pupils were E. histolytica/dispar 512 (25.4\%) and G. duodenalis 139 (6.9\%). Mixed STH and intestinal protozoan coinfections were detected in 295 (14.6\%) of the study participants (Table 2).

Ascaris lumbricoides, hookworm, and E. hist/dispar prevalence varied significantly $(p<0.05)$ among the four communities. The children of Mbessa had the highest prevalence of STH (30.2\%), A. lumbricoides (24.9\%), and STH/intestinal protozoa coinfection (24.9\%), while those in Nkor had highest prevalence of $E$. hist/dispar (36\%) and intestinal protozoa $(40.5 \%)$ when compared with those of the other communities (Table 3).

Infection with E. histolytica/dispar and A. lumbricoides was statistically and clinically dependent on age and sex, while the rest of the intestinal protozoa infections were not (Table 2).

3.3. Association of STH, Intestinal Protozoan, and Anaemia with Age and Sex. Four hundred and sixty-seven (23.1\%) of the pupils were anaemic (Table 2), with majority of the females (53.5\%) being more anaemic than males. Although not statistically significant, the prevalence of anaemia was higher in the 5-15 years age group (93.4\%) than those in the 3-4 years age group (6.6\%). The occurrence of anaemia in association with age and sex was statistically independent, but clinically dependent. Significantly $(p<0.001)$ higher prevalence of anaemia was observed in children of the Kumbo community (32.7\%) when compared with those of Djottin (17.8\%), Mbessa (12.4\%), and Nkor (18.4\%) as revealed in Table 3.

Moderate anaemia occurred commonly (13.5\%) in the participants than mild $(8.7 \%)$ and severe anaemia $(0.9 \%)$. Significant $(p<0.001)$ differences in anaemia severity were observed by community, and the prevalence of moderate anaemia was highest in children of the Kumbo community (20\%) compared to the other communities Table 3. Overall, the mean (SD) haemoglobin varied significantly $(p<0.05)$ with $A$. lumbricoides, hookworm, intestinal protozoa infections, and STH/intestinal protozoa coinfection with the higher levels occurring in children without these infections. The multinomial linear regression model indicated that anaemia was significantly $(p<0.05)$ more frequent in pupils infected with A. lumbricoides, S. stercoralis, and hookworm as well as E. hist/dispar and G. duodenalis (Table 2). 
TABLE 2: Prevalence of intestinal protozoan and STH infections according to the surveyed localities.

\begin{tabular}{|c|c|c|c|c|c|c|}
\hline Variable & Djottin & Kumbo & Mbessa & Nkor & Total & $p$ value \\
\hline \multicolumn{7}{|l|}{ Soil-transmitted helminth } \\
\hline Ascaris lumbricoides N (\%) & $62(14.7)$ & $72(8.5)$ & $94(24.9)$ & $76(20.3)$ & $304(15.1)$ & $<0.001$ \\
\hline Hookworm $N(\%)$ & $13(3.1)$ & $6(0.7)$ & $10(2.6)$ & $12(3.2)$ & $41(2.0)$ & 0.005 \\
\hline Strongyloides stercoralis N (\%) & $3(0.7)$ & $3(0.4)$ & $3(0.8)$ & $8(2.1)$ & $17(0.8)$ & 0.019 \\
\hline Trichuris trichiura $N(\%)$ & $1(0.2)$ & $0(0.0)$ & $7(1.9)$ & $9(2.4)$ & $17(0.8)$ & $<0.001$ \\
\hline At least one STH & $74(17.5)$ & $81(9.6)$ & $114(30.2)$ & $100(26.7)$ & $369(18.3)$ & $<0.001$ \\
\hline STH/IP coinfection & $62(14.7)$ & $57(6.8)$ & $94(24.9)$ & $82(21.9)$ & $295(14.6)$ & $<0.001$ \\
\hline \multicolumn{7}{|l|}{ Intestinal protozoa } \\
\hline Entamoeba hist/dispar N (\%) & $131(31.0)$ & $122(14.5)$ & $124(32.8)$ & $135(36.0)$ & $512(25.4)$ & $<0.001$ \\
\hline Giardia duodenalis N (\%) & $33(7.8)$ & $55(6.5)$ & $28(7.4)$ & $23(6.1)$ & $139(6.9)$ & 0.744 \\
\hline At least one intestinal protozoan & $159(37.7)$ & $168(19.9)$ & $147(38.9)$ & $152(40.5)$ & $626(31.0)$ & $<0.001$ \\
\hline \multicolumn{7}{|l|}{ Anaemia } \\
\hline Severe & $3(0.7)$ & $8(0.9)$ & $4(1.1)$ & $4(1.1)$ & $19(0.9)$ & $<0.001$ \\
\hline Moderate & $38(9.0)$ & $169(20.0)$ & $23(6.1)$ & $42(11.2)$ & $272(13.5)$ & \\
\hline Mild & $34(8.1)$ & $99(11.7)$ & $20(5.3)$ & $23(6.1)$ & $176(8.7)$ & \\
\hline Total & $75(17.8)$ & $276(32.7)$ & $47(12.4)$ & $69(18.4)$ & $467(23.1)$ & \\
\hline Total & 422 & 843 & 378 & 375 & & \\
\hline
\end{tabular}

STH: soil-transmitted helminths; IP: intestinal protozoa; boldface numbers indicate significant $p$ values.

TABLE 3: Association of haemoglobin with age, sex, and intestinal parasites.

\begin{tabular}{|c|c|c|c|c|c|c|c|}
\hline \multirow[b]{2}{*}{ Variable } & \multirow[b]{2}{*}{ Subclass } & \multirow[b]{2}{*}{ Total (\%) } & \multirow{2}{*}{$\begin{array}{c}\mathrm{Hb}(\mathrm{g} / \mathrm{dL}) \\
\bar{x} \pm \mathrm{SD}\end{array}$} & \multicolumn{2}{|c|}{ Anaemia } & \multirow[b]{2}{*}{$p$ value } & \multirow[b]{2}{*}{ O.R (95\% C.I) } \\
\hline & & & & Positive (\%) & Negative (\%) & & \\
\hline \multirow{2}{*}{ Age groups } & Toddlers & $110(5.5)$ & $12.12 \pm 1.98$ & $31(6.6)$ & $79(5.1)$ & 0.197 & $1.3(0.9-2.0)$ \\
\hline & Adolescents & $1908(94.5)$ & $12.99 \pm 2.06$ & $436(93.4)$ & $1472(94.9)$ & Ref & 1.0 \\
\hline \multirow{2}{*}{ Sex } & Female & $1029(51.0)$ & $12.73 \pm 1.96$ & $250(53.5)$ & $779(50.2)$ & 0.210 & $1.1(0.9-1.4)$ \\
\hline & Male & $998(49.0)$ & $13.17 \pm 2.15$ & $217(46.5)$ & $772(49.8)$ & Ref & 1.0 \\
\hline \multirow{4}{*}{ STH } & Ascaris lumbricoides & $304(15.1)$ & $12.37 \pm 2.18$ & $105(22.5)$ & $199(12.8)$ & $<0.001$ & $1.9(1.5-2.6)$ \\
\hline & Strongyloides stercoralis & $17(0.8)$ & $12.21 \pm 2.87$ & $10(2.1)$ & $7(0.5)$ & $<0.001$ & $4.8(1.8-12.7)$ \\
\hline & Hookworm & $41(2.0)$ & $12.01 \pm 2.54$ & $17(3.6)$ & $24(1.5)$ & 0.005 & $2.4(1.3-4.5)$ \\
\hline & Trichuris trichiura & $17(0.8)$ & $12.45 \pm 1.76$ & $3(0.6)$ & $14(0.9)$ & 0.590 & $0.7(0.2-2.5)$ \\
\hline \multirow{2}{*}{ Intestinal protozoa } & Entamoeba hist/dispar & $512(25.4)$ & $12.61 \pm 2.15$ & $140(30.0)$ & $372(24.0)$ & 0.009 & $1.3(1.1-1.7)$ \\
\hline & Giardia duodenalis & $139(6.9)$ & $12.30 \pm 2.14$ & $47(10.1)$ & $92(5.9)$ & 0.002 & $1.8(1.2-2.6)$ \\
\hline \multirow{3}{*}{ STH/IP coinfection } & Positive & $295(14.6)$ & $12.29 \pm 2.15$ & $101(21.6)$ & $194(12.5)$ & $<0.001$ & $2.0(1.5-2.5)$ \\
\hline & Negative & $1723(85.4)$ & $13.06 \pm 2.04$ & $366(78.4)$ & $1357(87.5)$ & Ref & 1.0 \\
\hline & Total & 2018 & $12.95 \pm 2.07$ & 467 & 1551 & & \\
\hline
\end{tabular}

STH: soil-transmitted helminths; IP: intestinal protozoa; O.R: odds ratio; 95\% C.I.: 95\% confidence interval; $\bar{x}$ : mean; SD: standard deviation; boldface numbers indicate significant $p$ values.

\section{Discussion}

The WHO estimates that about 267 million preschool age children and 568 million school-aged children are at risk of parasitic infections in Africa with the consequence of chronic infections being anaemia [10]. The aim of the current study was to investigate the prevalence of STH, protozoa, and their association with anaemia in primary school pupils in four communities with different environmental and sanitation conditions.
The results in Djottin, Kumbo, Mbessa, and Nkor showed that STH, intestinal protozoa, and anaemia were endemic in all four communities, but with relatively high levels of anaemia. The average prevalence in each community was below $1 \%$ for all four STH species and 7\% for the two intestinal protozoa species. However, due to the typical nature of transmission, high endemicity of STH and intestinal protozoa were found in Mbessa and Nkor, respectively. When comparing our results with previous studies nationwide, the $18.3 \%$ 
prevalence of at least one STH in this study appears to be higher than the $1-16.6 \%$ reported $[4,14,26,28,37,38]$ and lower than the $24.1-81.6 \%$ reported in other studies [4, 6, 9, $17,39]$. Compared to similar studies, we found STH endemicity similar to that in other countries $[12,20,21,40]$, as well as higher $[9,15,17,40]$.

With regard to STH species, A. lumbricoides was predominant with a prevalence of $15.1 \%$ followed by hookworm (2\%), S. stercoralis $(0.8 \%)$, and T. trichiura (0.8\%). The prevalence of ascariasis in our study was higher compared to the $1-12 \%[26,37-39,41,42]$ and lower than the $18-73.5 \%$ reported in other localities in Cameroon [4, 6, 41, 43, 44]. Out of Cameroon, it was higher compared to the $0.3-8.2 \%$ rates reported in North-Western Tanzania, rural Laos, Cuba, and Cambodia $[11,20,45,46]$ and lower compared to the $17.5-62 \%$ reported worldwide $[9,12,15,17,21,24,40,47$, 48]. The hookworm prevalence of $2 \%$ in this study was higher compared to the $0-1.6 \%[9,11,23,38-41,47,48]$ and lower compared to the $7.5-51.7 \%$ reported in and out of Cameroon $[4,6,12,15,17,20,21,24,43,45]$. Parasitic infections in general result from poor sanitation and hygienic conditions with higher prevalence in areas with the poor hygienic conditions $[6,26,37]$ accounting for the varying prevalence according to community. The higher prevalence of $A$. lumbricoides in this study can be accounted for by the timing of the study (between December and April which matches the peak season as confirmed by hospital records) and by the fact that ascaris is predominant in areas of poor sanitation as is the case with these study sites. The differences in the prevalence of ascaris could be explained by the fact that the present study was a community-based study in which asymptomatic primary school pupils were enrolled by simple random sampling, compared to other studies in which whole schools/communities or hospitalized patients were enrolled. In this study, STH infection had was associated with anaemia unlike the case in a study in Ethiopia [15]. Occurring in SAC, infections with STH and/or protozoan will hinder the uptake of iron and consequently lead to iron deficiency anaemia and thus stunting, wasting, and underweight $[16,18,49]$. Ascariasis as well as the other STH infections can also give rise to disability-adjusted life-years [5].

The overall endemicity of protozoa in this study of $31 \%$ was higher than the $1019.7 \%$ reported in Cameroon and abroad $[6,12,48,50]$. In this study, the prevalence of E. hist/dispar was $25.4 \%$ which was similar to the $25.3 \%$ reported amongst urban slum dwellers in Nigeria [47], higher compared to the $0.1-19.7 \%$ reported in rural Laos, Southern Angola, and amongst university students in Ethiopia and in Malaysia [12, 20, 48, 50], and lower compared to the $66.5 \%$ reported amongst residents of Plateau Central and CentreOuest Bukina Faso [23]. The prevalence of G. duodenalis in this study was $69 \%$ which was similar to the $68.9 \%$ reported in rural Laos [20] and very high compared to rates reported elsewhere out of Cameroon; 3.5-20.1\% [12, 47, 48, 50]. Although environmental factors were not considered, most of these intestinal parasites are transmitted in areas with poor hygienic conditions and poor water supply, and these areas have acute water crisis especially in the dry season.

Our findings indicated that pupils infected with the STHs, A. lumbricoides and hookworm, as well as with the protozoan,
E. hist/dispar and G. duodenalis, were more likely to suffer from iron deficiency anaemia, which is similar to findings reported in Malaysia [17]. Anaemia prevalence of $23.1 \%$ is in line with $24.6 \%$ reported amongst prison inmates in Douala [28] and 21.6\% reported in Southern Angola [48], higher than the $15.4 \%$ reported among SAC in Ethiopia [15] and lower than the 29.43-85.2\% reported amongst school children in Cameroon, Africa, and Asia [6, 12-14, 23]. The differences in the prevalence of anaemia could be explained by the fact that the present study was a community-based study in which asymptomatic primary school pupils were enrolled by simple random sampling with a larger sample size compared to other studies in which whole schools/communities or hospitalized patients were enrolled as well as others wherein malaria was considered to be a risk factor of anaemia.

\section{Recommendations}

Pivotal to assessing the prevalence rates of infections and understanding the anaemic states of the pupils is obtaining epidemiological data for the communities. These findings underline the need for continuous intervention programmes to enhance deworming. Health education on personal sanitation, environmental sanitation, and the regular use of preventive chemotherapy should be encouraged. This study also suggests the need for an elaborate investigation of a relationship between STH, intestinal protozoa with the absenteeism recorded in schools, and their anthropometric parameters.

\section{Strengths and Limitations}

6.1. Strengths of the Study. Field and laboratory data were obtained by well-trained Clinical Laboratory Technicians, who had a mastery of the study area as well as microscopy and spectroscopy.

6.2. Limitations of the Study. This study did not consider anthropometric measurements of the pupils nor did it follow the absenteeism recorded by pupils, hence an underestimation of the role of STH and intestinal protozoa on the physical wellbeing of primary school pupils and their school attendance in the communities. Although we took note of no deworming within the last two years, we neither collected data on socioeconomic factors, nor private/personal deworming strategies, nor physical examination/clinical data to evaluate the severity of anaemia, as well as predisposing factors from schools; hence, their outcomes cannot be related to socio-economic and environmental predisposing factors.

\section{Conclusions}

This is the first study providing a comprehensive soiltransmitted helminth and intestinal protozoan infection profile in primary school children in four communities in the North West Region of Cameroon. Our study shows that STH and intestinal protozoa infections are associated with sex, age, and community. It also demonstrates that the study participants who were infected with A. lumbricoides, hookworm, and the pathogenic entamoeba were more likely to suffer from anaemia. The occurrence of anaemia amongst 
the pupils represents a challenge, due to multiple host parasitic infections and a potential unmeasured malnutrition. Thus, this study recommends continuous deworming and health education on personal and environmental sanitation.

$\begin{array}{ll}\text { Abbreviations } \\ \text { 95\% C.I: } & 95 \% \text { confidence interval } \\ \text { MOH: } & \text { Ministry of Health } \\ \text { O.R: } & \text { Odds ratio } \\ p: & \text { Significance value } \\ \text { STHs: } & \text { Soil-transmitted helminths } \\ \text { SD: } & \text { Standard deviation } \\ \text { WHO: } & \text { World Health Organization } \\ \chi^{2}: & \text { Chi square. }\end{array}$

\section{Data Availability}

The data are found in STH and PP S1.pdf.

\section{Ethical Approval}

This study was approved by the Divisional Delegates of Basic Education and the Educational Authorities for the Baptist and Catholic schools.

\section{Conflicts of Interest}

The authors declare that they have no competing interests.

\section{Authors' Contributions}

Conceptualisation and methodology were performed by FNC and PKJ; laboratory analysis by FNC, HNN, RTB, RSK, BTT, and PKJ; data curation by FNC and PKJ; statistical analysis by FNC, DA, PNF, and PKJ; original draft preparation by FNC, PNF, and PKJ; review and editing of draft by FNC, DA, PNF, and PKJ; and administration and supervision by FNC and PKJ. All authors read and approved the final manuscript. Humphrey Ngala Ngala, Ranibell Tung Bongazi, Rogers Sanga Kinsam, Beltha Tahnteng Tata, Frederick Nchang Cho, and Patrick Kofon Jokwi contributed equally to this work.

\section{Acknowledgments}

We are thankful to our participants for accepting to participate in the study. We are grateful to all the headteachers of schools for coordinating the pupils for health education and specimen collection. Lastly, we express immense gratitude to the parents/guardians of pupils for allowing their children to participated in the study.

\section{Supplementary Materials}

\section{STH and PP S1. (Supplementary Materials)}

\section{References}

[1] R. B. Sah, R. Baral, U. Shah, and N. Jha, "A study of prevalence of intestinal protozoan infections and associated risk factors among the school children of Biratnagar Submetropolitan, eastern region of Nepal," Asian Pacific Journal of Health Sciences, vol. 3, no. 1, pp. 181-187, 2016.

[2] WHO, Soil-transmitted helminthiases: eliminating soiltransmitted helminthiases as a public health problem in children: progress report 2001-2010 and strategic plan 2011-2020, World Health Organization, France, 2012.

[3] T. Kuete, F. L. S. Yemeli, E. E. Mvoa, T. Nkoa, R. M. Somo, and A. S. Ekobo, "Prevalence and risk factors of intestinal helminth and protozoa infections in an urban setting of Cameroon: the case of Douala," American Journal of Epidemiology and Infectious Disease, vol. 3, no. 2, pp. 36-44, 2015.

[4] L. A. Tchuem Tchuenté, C. Dongmo Noumedem, P. Ngassam et al., "Mapping of schistosomiasis and soil-transmitted helminthiasis in the regions of Littoral, North-West, South and South-West Cameroon and recommendations for treatment," BMC Infectious Diseases, vol. 13, no. 1, 2013.

[5] P. M. Jourdan, P. H. L. Lamberton, A. Fenwick, and D. G. Addiss, "Soil-transmitted helminth infections," Lancet, vol. 391, no. 10117, pp. 252-265, 2018.

[6] A. L. Njunda, S. G. Fon, J. C. Assob, D. S. Nsagha, T. D. Kwenti, and T. E. Kwenti, "Coinfection with malaria and intestinal parasites, and its association with anaemia in children in Cameroon," Infectious Diseases of Poverty, vol. 4, no. 1, 2015.

[7] C. Njua-Yafi, E. A. Achidi, J. K. Anchang-Kimbi et al., "Malaria, helminths, co-infection and anaemia in a cohort of children from Mutengene, south western Cameroon," Malaria Journal, vol. 15, no. 1, 2016.

[8] S. Brooker, A. C. A. Clements, and D. A. P. Bundy, "Global epidemiology, ecology and control of soil-transmitted helminth infections," Advances in Parasitology, vol. 62, pp. 221-261, 2006.

[9] R. M. Nguema, J. F. Mavoungou, K. M. M. Ngou-Milama et al., "Baseline mapping of schistosomiasis and soil transmitted helminthiasis in the northern and eastern health regions of Gabon, Central Africa: recommendations for preventive chemotherapy," Tropical Medicine and Infectious Disease, vol. 3, no. 4, 2018.

[10] WHO, Soil-transmitted helminth infections, W. F. Sheet, Ed., World Health Organization, Geneva, 2020.

[11] D. Z. Munisi, J. Buza, E. A. Mpolya, and S. M. Kinung'hi, "Schistosoma mansoni infections, undernutrition and anaemia among primary schoolchildren in two onshore villages in Rorya District, North-Western Tanzania," PLoS One, vol. 11, no. 12, article e0167122, 2016.

[12] Y. Rajoo, S. Ambu, Y. A. Lim et al., "Neglected intestinal parasites, malnutrition and associated key factors: a population based cross-sectional study among indigenous communities in Sarawak, Malaysia," PLOS ONE, vol. 12, no. 1, article e0170174, 2017.

[13] P. Ncogo, M. Romay-Barja, A. Benito et al., "Prevalence of anemia and associated factors in children living in urban and rural settings from Bata District, Equatorial Guinea, 2013," PLoS One, vol. 12, no. 5, article e0176613, 2017.

[14] I. U. N. Sumbele, A. J. Nkain, T. R. Ning, J. K. Anchang-Kimbi, and H. K. Kimbi, "Influence of malaria, soil-transmitted helminths and malnutrition on haemoglobin level among school-aged children in Muyuka, Southwest Cameroon: a cross-sectional study on outcomes," PLoS One, vol. 15, no. 3, article e0230882, 2020.

[15] E. Molla and H. Mamo, "Soil-transmitted helminth infections, anemia and undernutrition among schoolchildren in 
Yirgacheffee, South Ethiopia," BMC Research Notes, vol. 11, no. 1, p. 585, 2018.

[16] J. G. Shaw and J. F. Friedman, "Iron deficiency anemia: focus on infectious diseases in lesser developed countries," Anemia, vol. 2011, Article ID 260380, 10 pages, 2011.

[17] R. Ngui, Y. A. L. Lim, L. Chong Kin, C. Sek Chuen, and S. Jaffar, "Association between anaemia, iron deficiency anaemia, neglected parasitic infections and socioeconomic factors in rural children of West Malaysia," PLoS Neglected Tropical Diseases, vol. 6, no. 3, article e1550, 2012.

[18] C. M. Chaparro and P. S. Suchdev, "Anemia epidemiology, pathophysiology, and etiology in low- and middle-income countries," Annals of the New York Academy of Sciences, vol. 1450, no. 1, pp. 15-31, 2019.

[19] S. Sayasone, T. K. Mak, M. Vanmany et al., "Helminth and intestinal protozoa infections, multiparasitism and risk factors in Champasack province, Lao People's Democratic Republic," PLoS Neglected Tropical Diseases, vol. 5, no. 4, article e1037, 2011.

[20] A. N. Chard, K. K. Baker, K. Tsai et al., "Associations between soil-transmitted helminthiasis and viral, bacterial, and protozoal enteroinfections: a cross-sectional study in rural Laos," Parasites \& Vectors, vol. 12, no. 1, p. 216, 2019.

[21] A. E. Wiria, F. Hamid, L. J. Wammes et al., "Infection with soil-transmitted helminths is associated with increased insulin sensitivity," PLoS One, vol. 10, no. 6, article e0127746, 2015.

[22] T. Schmidlin, E. Hürlimann, K. D. Silué et al., "Effects of hygiene and defecation behavior on helminths and intestinal protozoa infections in Taabo, Côte d'Ivoire," PLoS ONE, vol. 8, no. 6, article e65722, 2013.

[23] S. Erismann, S. Diagbouga, P. Odermatt et al., "Prevalence of intestinal parasitic infections and associated risk factors among schoolchildren in the Plateau Central and Centre-Ouest regions of Burkina Faso," Parasites \& Vectors, vol. 9, no. 1, 2016.

[24] J. Vlaminck, O. Lagatie, A. Verheyen et al., "Patent infections with soil-transmitted helminths and Schistosoma mansoni are not associated with increased prevalence of antibodies to the Onchocerca volvulus peptide epitopes OvMP-1 and OvMP-23," Parasites \& Vectors, vol. 12, no. 1, p. 63, 2019.

[25] V. D. Makoge, G. A. Mbah, L. Nkengazong, N. E. Sahfe, and R. S. Moyou, "Falciparum malaria, helminth infection, and anaemia in asymptomatic pupils in four villages in Cameroon," European Journal of Zoological Research, vol. 1, no. 2, pp. 54-59, 2012.

[26] S. E. Ako, A. Edith, T. N. Vicky, A. N. Abiabia, and H. K. Kimbi, "Persistent soil-transmitted helminth infections and associated risk factors among children aged between 4 and 12 in mile 16 Bolifamba, Buea, Cameroon: 6 months postdeworming campaign," International Journal of TROPICAL DISEASE \& Health, vol. 32, no. 4, pp. 1-9, 2018.

[27] S. Brooker, C. A. Donnelly, and H. L. Guyatt, "Estimating the number of helminthic infections in the Republic of Cameroon from data on infection prevalence in schoolchildren," Bulletin of the World Health Organization, vol. 78, no. 12, pp. 14561465, 2007.

[28] T. Kuete, H. Ghislain Mbwang, C. Menengue Nguele, and A. Same Ekobo, "Prevalence of intestinal parasitic infections among inmates of the new-bell central prison, Cameroon," International Journal of TROPICAL DISEASE \& Health, vol. 35, no. 2, pp. 1-10, 2019.

[29] M. D. Oyono, L. G. Lehman, S. Fosso, and C. F. B. Bilong, "Multiparasitism among schoolchildren of Akonolinga,
Nyong et Mfoumou Division, Centre Region of Cameroon," bioRxiv, pp. 1-21, 2019.

[30] J. E. Bartlett, J. W. Kotrlik, and C. C. Higgins, “Organizational research: determining appropriate sample size in survey research," Information Technology Learning, and Performance Journal, vol. 19, no. 1, 2001.

[31] C. Kothari, Research methodology, methods \& techniques, New Age International (P) Ltd., Publishers, New Delhi, 2004.

[32] B. Shrestha and L. Dunn, "The declaration of helsinki on medical research involving human subjects: a review of seventh revision," Journal of Nepal Health Research Council, vol. 17, no. 4, pp. 548-552, 2019.

[33] NIS, Demographic and Health Survey and Multiple Indicators Cluster Survey DHS-MICS 2011, National Institute of Statistics, Yaoundé, Cameroon, 2012.

[34] M. Cheesbrough, District Laboratory Practice in Tropical Countries, vol. 1, Cambridge University Press, Cambridge, 2 edition, 2009.

[35] WHO, Manual of basic techniques for a health laboratory, World Health Organization, Geneva, 2 edition, 2003.

[36] M. Cheesbrough, District Laboratory Practice in Tropical Countries, vol. 2, Cambridge University Press, Cambridge, 2 edition, 2006.

[37] T. Egbe Sarah Balle, E. M. Eyong, E. A. Achidi, J. Löve, and S. N. Cumber, "soil-transmitted helminth infection in the Tiko Health District, South West Region of Cameroon: a postintervention survey on prevalence and intensity of infection among primary school children," The Pan African medical journal, vol. 30, no. 74, pp. 1-9, 2018.

[38] S. J. Campbell, J. R. Stothard, F. O'Halloran et al., "Urogenital schistosomiasis and soil-transmitted helminthiasis (STH) in Cameroon: an epidemiological update at Barombi Mbo and Barombi Kotto crater lakes assessing prospects for intensified control interventions," Infectious Diseases of Poverty, vol. 6, no. $1,2017$.

[39] L. A. Tchuem Tchuenté, R. I. Kamwa Ngassam, L. Sumo et al., "Mapping of schistosomiasis and soil-transmitted helminthiasis in the regions of centre, east and west Cameroon," PLoS Neglected Tropical Diseases, vol. 6, no. 3, article e1553, 2012.

[40] J. A. Gabrie, M. M. Rueda, C. A. Rodríguez, M. Canales, and A. L. Sanchez, "Immune profile of Honduran schoolchildren with intestinal parasites: the skewed response against geohelminths," Journal of Parasitology Research, vol. 2016, Article ID 1769585, 13 pages, 2016.

[41] I. U. Sumbele, G. B. Nkemnji, and H. K. Kimbi, "Soil-transmitted helminths and plasmodium falciparum malaria among individuals living in different agroecosystems in two rural communities in the Mount Cameroon area: a cross-sectional study," Infectious Diseases of Poverty, vol. 6, no. 1, p. 67, 2017.

[42] L. Djune-Yemeli, H. C. Nana-Djeunga, C. G. Lenou-Nanga et al., "Serious limitations of the current strategy to control soil-transmitted helminths and added value of ivermectin/albendazole mass administration: a population-based observational study in Cameroon," PLoS Neglected Tropical Diseases, vol. 14, no. 11, article e0008794, 2020.

[43] J. Bopda, H. Nana-Djeunga, J. Tenaguem et al., "Prevalence and intensity of human soil transmitted helminth infections in the Akonolinga health district (Centre Region, Cameroon): are adult hosts contributing in the persistence of the transmission?," Parasite Epidemiology and Control, vol. 1, no. 2, pp. 199-204, 2016. 
[44] J. V. Mbuh, N. H. Ntonifor, and J. Ojong, "The epidemiology of soil-transmitted helminth and protozoan infections in south-west Cameroon," Journal of Helminthology, vol. 86, no. 1, pp. 30-37, 2012.

[45] B. de Gier, G. M. Pita-Rodríguez, M. Campos-Ponce et al., "Soil-transmitted helminth infections and intestinal and systemic inflammation in schoolchildren," Acta Tropica, vol. 182, pp. 124-127, 2018.

[46] S. A. Schüle, P. Clowes, I. Kroidl et al., "Ascaris lumbricoides infection and its relation to environmental factors in the Mbeya region of Tanzania, a cross-sectional, populationbased study," PLoS ONE, vol. 9, no. 3, article e92032, 2014.

[47] V. P. Gyang, T.-W. Chuang, C.-W. Liao et al., "Intestinal parasitic infections: current status and associated risk factors among school aged children in an archetypal African urban slum in Nigeria," Journal of Microbiology, Immunology and Infection, vol. 52, no. 1, pp. 106-113, 2019.

[48] D. Oliveira, F. S. Ferreira, J. Atouguia, F. Fortes, A. Guerra, and S. Centeno-Lima, "Infection by intestinal parasites, stunting and anemia in school-aged children from southern Angola," PLoS One, vol. 10, no. 9, article e0137327, 2015.

[49] D. M. Darlan, F. R. Ananda, M. I. Sari, N. K. Arrasyid, and D. I. Sari, "Correlation between iron deficiency anemia and intestinal parasitic infection in school-age children in Medan," IOP Conference Series: Earth and Environmental Science, vol. 125, article 012059, 2018.

[50] B. H. Ayele, A. Geleto, A. Ayana, and M. Redi, "Prevalence of feco-oral transmitted protozoan infections and associated factors among university students in Ethiopia: a cross-sectional study," BMC Infectious Diseases, vol. 19, no. 1, 2019. 